\title{
The Effect of Epidural Anesthesia on Muscle Flap Tolerance to Venous Ischemia
}

\author{
Cenk Cayci, M.D. \\ Can Cinar, M.D. \\ Osman A. Yucel, M.D. \\ Turgay Tekinay, Ph.D. \\ Jeffrey A. Ascherman, M.D. \\ New York, N.Y.; and Istanbul and \\ Ankara, Turkey
}

Background: Venous ischemia is a major cause of failure after free tissue transfers and replantations. The combination of general and epidural anesthesia leads to vasodilatation and improves tissue perfusion. Postoperative pain relief and sympathetic blockage are additional benefits of epidural anesthesia. The purpose of this study was to determine whether epidural anesthesia has benefits on microcirculation and neutrophil functions in muscle flaps subjected to venous ischemia.

Method: Thirty Sprague-Dawley rats were divided into three groups: group I, general anesthesia; group II, spinal anesthesia; and group III, epidural anesthesia. Cremaster flaps were prepared, postcapillary venules were selected under intravital videomicroscopy, and flaps were subjected to venous ischemia. Images were recorded from preselected postcapillary venules before venous ischemia (baseline) and following reperfusion. Neutrophil rolling and adhesion, functional capillary density, and diameters of postcapillary venules were evaluated.

Results: The increase in rolling neutrophils in group III was significantly lower than in groups I and II at 60 and 120 minutes. Change of adherent neutrophils in group III was significantly lower than in groups I and II at 15, 60 and 120 minutes. There was significantly more reduction in inner diameter of postcapillary venules in groups I and II compared with group III. Functional capillary density in groups I and II was significantly lower than in group III.

Conclusion: Epidural anesthesia regulated neutrophil functions, salvaged functional capillaries, and prevented vasoconstriction of postcapillary venules in cremaster muscle flaps subjected to venous ischemia. Spinal and general anesthesia, however, were found to be ineffective in improving microcirculation of muscle flaps subjected to venous ischemia. (Plast. Reconstr. Surg. 125: 89, 2010.)
M icrosurgical methods are used for a variety of purposes. Although advancements in microsurgical techniques have improved the success of microsurgical tissue transfer, reperfusion injury following ischemia is still a major cause of morbidity, prolonged hospitalization, and higher costs.

From the Department of Surgery, New York Presbyterian Hospital-Weill Cornell Medical College, the Division of Plastic Surgery, New York Presbyterian Hospital-Columbia University Medical Center, the Department of Plastic and Reconstructive Surgery, I.U. Cerrahpasa Medical School, and the UNAM, Institute of Materials Science and Nanotechnology, Bilkent University.

Received for publication February 1, 2009; accepted July 15, 2009.

Presented at the 24th National Congress of the Turkish Society of Plastic, Reconstructive and Aesthetic Surgery, in Ankara, Turkey, October 25 through 29, 2002, and awarded the prize for the second best experimental research paper in the residents category.

Copyright (C2009 by the American Society of Plastic Surgeons

DOI: 10.1097/PRS.0b013e3181c49544
Tissues are more tolerant to primary ischemia than venous ischemia. ${ }^{1}$ Secondary ischemia associated with venous dysfunction is observed more frequently and causes more serious damage than arterial or global ischemia. ${ }^{2}$ Venous ischemia usually occurs due to errors in microvascular surgical methods. Venous obstruction causes venous pooling, cessation of arterial flow, extravasation of both erythrocytes and neutrophils, deposition of fibrin, and thrombus formation. The tissue damage is progressive and tissue necrosis may develop even after restoration of the venous flow (no-reflow phenomenon). ${ }^{3-5}$ Although the mechanism of this tissue damage is not completely understood, it was shown in various studies that lipid

Disclosures: This study was supported by departmental funds. None of the authors has a financial interest in any of the products, devices, or drugs mentioned in this article. 
peroxidation, ${ }^{6,7}$ prostanoid mechanisms,${ }^{8}$ and free radicals have important roles in its pathophysiology. The course of the necrosis is different from the all-or-none phenomenon observed in global or arterial ischemia.

There is a debate on selection of the best anesthesia technique and anesthetic drugs in microvascular surgery. ${ }^{9-11}$ When used concurrently with general anesthesia, epidural anesthesia may lead to vasodilatation that increases perfusion and regulates microcirculation, and provides effective pain control in the postoperative period. However, with regard to regional anesthesia being an ideal method for anesthesia in microsurgery, there is ongoing debate, and controversial data exist in the literature..$^{9,10,12-16}$ The objective of this study was to determine whether the positive effects of epidural anesthesia on microcirculation would improve circulation in flaps with venous ischemia.

\section{MATERIALS AND METHODS}

Thirty male Sprague-Dawley rats, weighing $175 \pm 36.3 \mathrm{~g}$, were divided into three groups: general anesthesia in group I $(n=10)$, spinal anesthesia in group II $(n=10)$, and epidural anesthesia in group III $(n=10)$. All experiments were performed according to protocols approved by the Institutional Animal Care and Use Committee and complied with the Guide for the Care and Use of Laboratory Animals.

Placement of epidural and spinal catheters was done as described by Bahar et al. ${ }^{17} 50 \mu \mathrm{l}$ and $25 \mu \mathrm{l}$ of lidocaine 2\% (Jetokain; Adeka Ltd., Samsun, Turkey) were administered via a catheter for epidural (group III) and spinal anesthesia (group II), respectively. Lidocaine injection at a rate of 10 $\mu \mathrm{l} /$ minute was continued until the rat was not carrying its own weight and lied down with its belly and chest on the ground. General anesthesia was achieved with intramuscular ketamine $6 \mathrm{mg} / \mathrm{kg}$ (Ketalar; Pfizer, New York, N.Y.) and xylazine 0.4 $\mathrm{mg} / \mathrm{kg}$ (Rompun; Bayer, Leverkusen, Germany).

The rat cremaster muscle island flap was prepared as described by Grant et al. ${ }^{18,19}$ The vascular pedicle was completely skeletonized during the dissection, rendering the flap microvasculature completely denervated. In group I, all flaps were elevated under general anesthesia. In groups II and III, spinal and epidural catheters were first placed under general anesthesia. In these groups, the flap elevation procedure was delayed for 24 hours to exclude the rats that developed neurologic deficits and to be sure that the rats totally recovered from general anesthesia. Cremaster flaps were then harvested under spinal and epi- dural anesthesia. ${ }^{18,20}$ Rats were placed on a fixed stage under the microscope. The muscle flap was secured on an upside down Petri dish by 5-0 nylon sutures (Fig. 1). The cremaster muscle flap was covered with a stretch film and kept in distilled water for 24 hours to avoid drying. The muscle was kept moist with lactated Ringer's solution.

To evaluate tissue response to secondary venous ischemia, microcirculation of cremaster muscles was assessed by using intravital videomicroscopy. The optic apparatus of the intravital videomicroscopy consisted of an Olympus light microscope, CX41 $(4 \times, 10 \times, 40 \times, 100 \times)$, equipped with a custom-made adaptor to ensure the connection with the ocular region of the digital video camera (Sony TRV 120E; Sony, Tokyo, Japan). The magnification was $1800 \times$ for the $40 \times$ objective of the light microscope.

After flap elevation and a 30-minute waiting period, a vascular map of each flap was prepared under $10 \times$ magnification. The postcapillary venules were determined for each flap for the measurement of experimental parameters, and were marked on the vascular map to relocate the same postcapillary venules for the subsequent reperfusion recordings. The baseline images were recorded from those veins for 45 seconds under $40 \times$ magnification. Afterward, 30 minutes of venous ischemia was created with a microvascular approximator clamp (vessel approximator clamp $0.4 \mathrm{~g} / \mathrm{mm}^{2}$; S\&T Marketing Ltd., Neuhausen, Switzerland) applied to the pudic-epigastric vein. After the release of the vascular clamp, recordings were made from the preselected postcapillary venules at 15,60 , and 120 minutes of reperfusion. The images were recorded on the videotapes for future

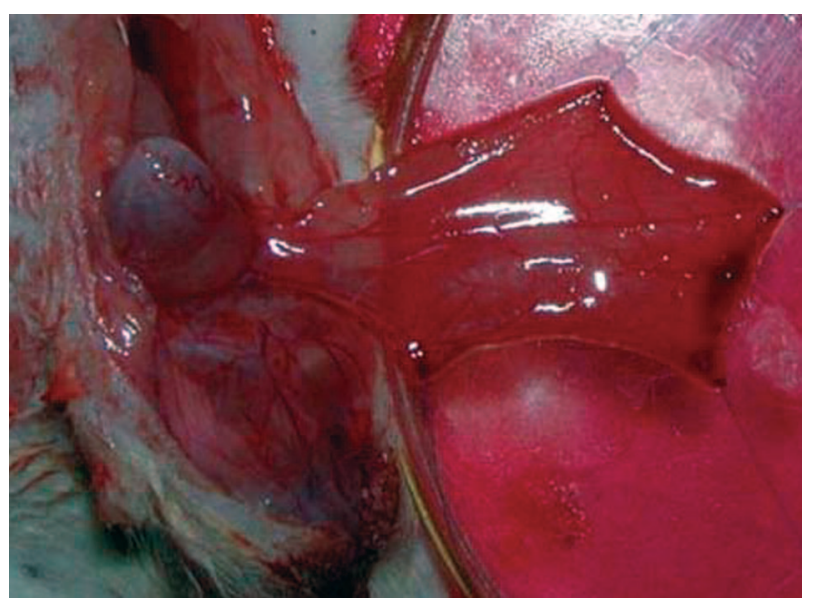

Fig. 1. The cremaster muscle flap was secured on an upside down Petri dish by 5-0 nylon sutures. The muscle was kept moist with lactated Ringer's solution. 
slow-motion evaluation by a blinded investigator for the following analyses:

Neutrophil rolling: Neutrophils making the characteristic rolling movement in the postcapillary venules were counted for 30 seconds.

Neutrophil adhesion: Neutrophils which already adhered, or were becoming adhered, to the endothelium within a certain area $(100 \mu \mathrm{m})$ of the postcapillary venules were counted for 30 seconds (Fig. 2).

Functional capillary density: Under $1800 \times$ magnification, nine areas from the distal, nine areas from the middle, and nine areas from the proximal part of each flap were evaluated for $15 \mathrm{sec}-$ onds each. Twenty-seven areas from every flap were thus examined, with each area measuring approximately $340 \times 420 \mu^{2}$. Functional capillaries with flow were recorded to estimate the functional capillary density for each flap. ${ }^{21}$

Postcapillary venule inner diameter change: Static images captured from the video images were analyzed by an image processing software (Image Tool version 2.0) to calculate the inner and outer diameter of postcapillary venules.

\section{Statistical Evaluation}

For the comparisons between the groups, measurements taken at minute 15 , first (minute 60), and second (minute 120) hours were standardized according to the baseline values (Delta- $\Delta$ values) of the same groups in the same postcapillary

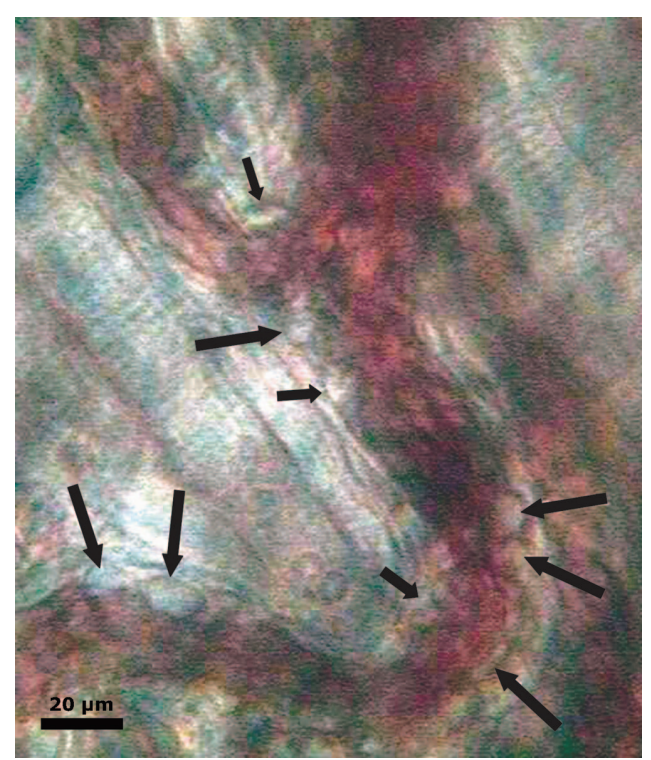

Fig. 2. Intravital videomicroscopic image showing rolling and adherent neutrophils (black arrows) to the postcapillary venules. Bar represents $20 \mu \mathrm{m}$. venules. No correction was made for multiple testing. Statistical analysis of the data were done using SPSS version 11.5 for Windows (SPSS, Inc., Chicago, Ill.). Comparisons within the groups were made by the $t$ test. Comparisons between the groups were performed with the analysis of variance test. The cut-off for significance was $p<0.05$.

\section{RESULTS}

\section{Neutrophil Behavior}

\section{Neutrophil Rolling}

Rolling neutrophil counts before venous ischemia and 15, 60, and 120 minutes after reperfusion are shown in Figure 3. In the epidural anesthesia group, there was no statistically significant increase in neutrophil rolling during reperfusion except at 15 minutes. Significant statistical differences were detected at 60 minutes and $120 \mathrm{~min}$ utes for the spinal and 60 and 120 minutes for the general anesthesia groups.

Intergroup evaluation revealed no significant differences between any of the groups at 15 minutes. No significant differences between the general and spinal anesthesia groups were detected at 60 minutes and at 120 minutes. Statistically significant differences between epidural anesthesia and general and spinal anesthesia groups at 60 and 120 minutes were detected (Fig. 4).

\section{Neutrophil Adhesion}

The number and course of the adherent neutrophils from the general, spinal, and epidural anesthesia groups recorded before venous ischemia (baseline) and at 15, 60, and 120 minutes of reperfusion are shown in Figure 5. In the epidural anesthesia group, no statistically significant differences were detected. In the general anesthesia group, the numbers of adherent neutrophils at 15, 60, and 120 minutes were significantly increased compared with the baseline levels. In the spinal anesthesia group, the numbers of neutrophils adherent to the endothelium significantly increased at 15,60 , and 120 minutes compared with the baseline levels.

Intergroup evaluation disclosed that there was no difference between the general and spinal anesthesia groups $(p>0.05)$. However, differences between epidural and general anesthesia were significant at 15, 60, and 120 minutes. The differences between epidural and spinal anesthesia groups were statistically significant at 15, 60, and 120 minutes (Fig. 6).

\section{Inner Diameter of Postcapillary Venules}

The changes in the postcapillary venule inner diameters compared with baseline diameters at 


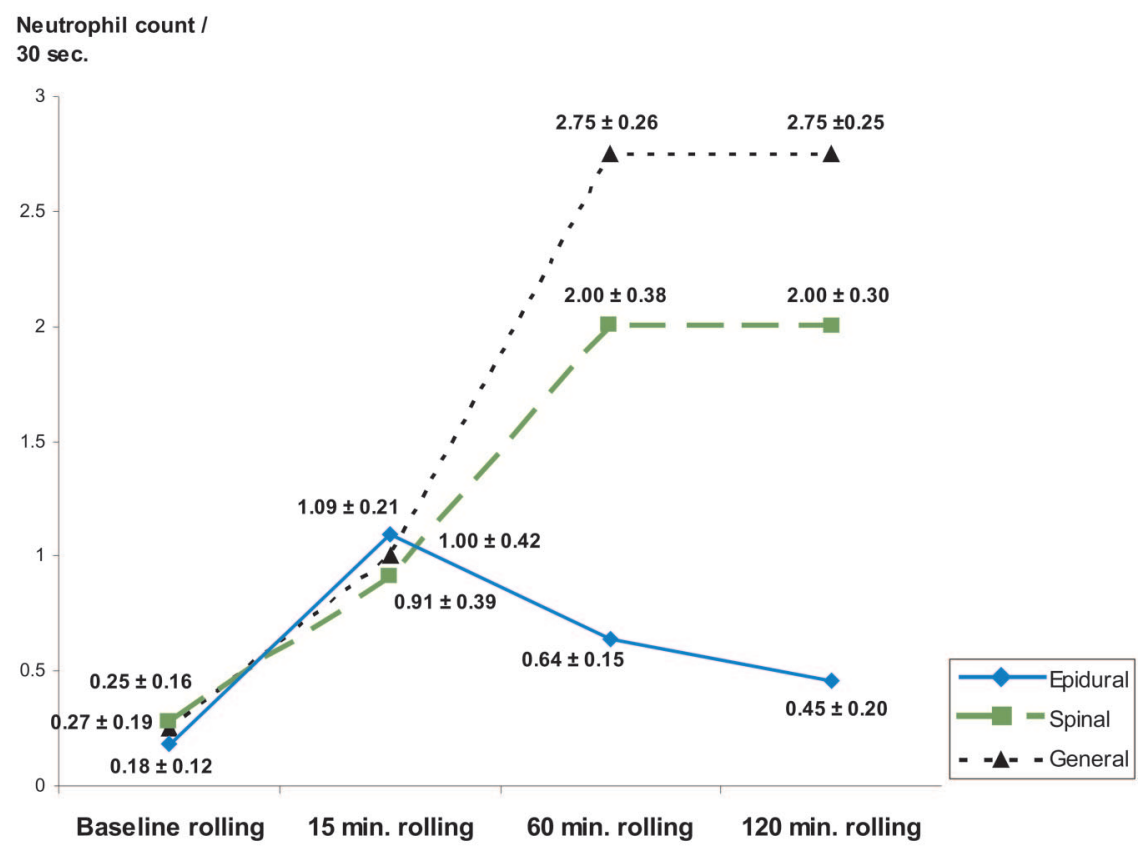

Fig. 3. Rolling neutrophil counts before venous ischemia and after reperfusion. Analysis within the groups revealed that the epidural anesthesia group had no statistically significant difference compared with baseline except at 15 minutes $(p<0.01)$. Both general and spinal anesthesia groups had significant differences compared with baseline at 60 and 120 minutes. Units for the numbers are number of neutrophils per 30 seconds; \pm values represent the standard error of mean ( $t$ test; ${ }^{*} p<0.05$ significant).

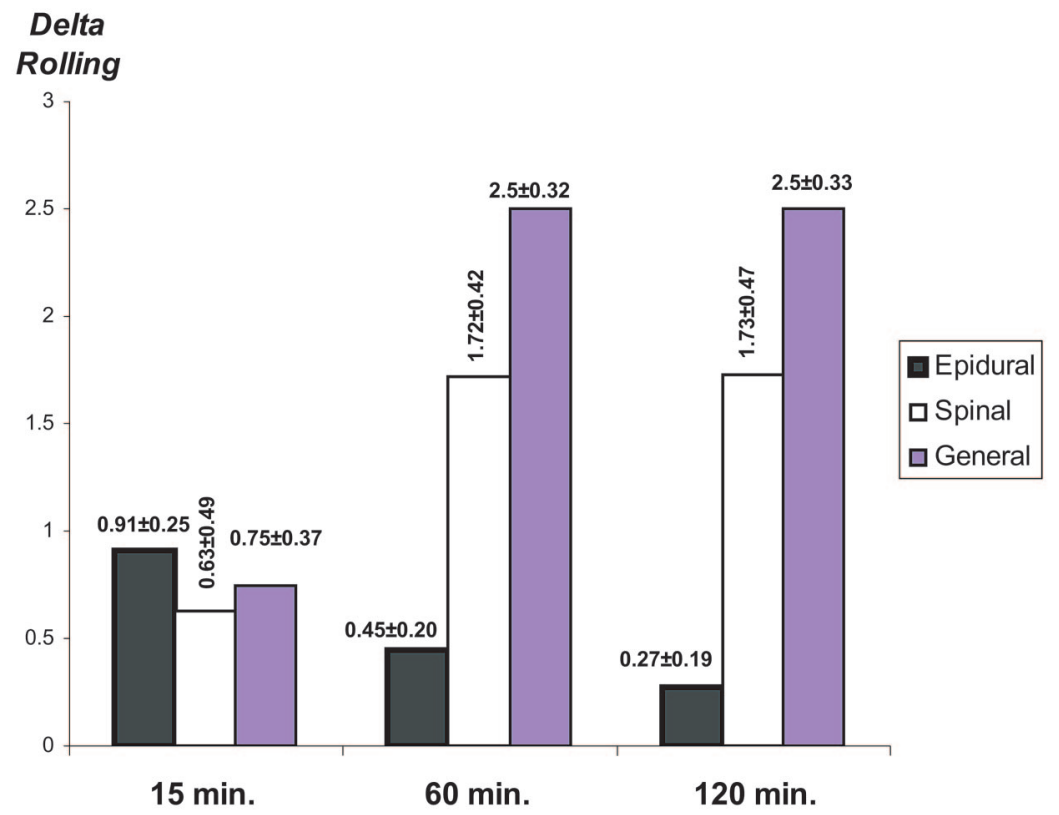

Fig. 4. Changes of rolling movements of the neutrophils compared with baseline $(\Delta$-rolling) in three groups were analyzed. No significant difference was detected at 15 minutes, but the epidural anesthesia group had significant differences compared with both general and spinal anesthesia at 60 and 120 minutes. Units for the numbers are number of neutrophils per 30 seconds; \pm values represent SEM (analysis of variance multiple comparison test; ${ }^{*} p<0.05$ significant). 


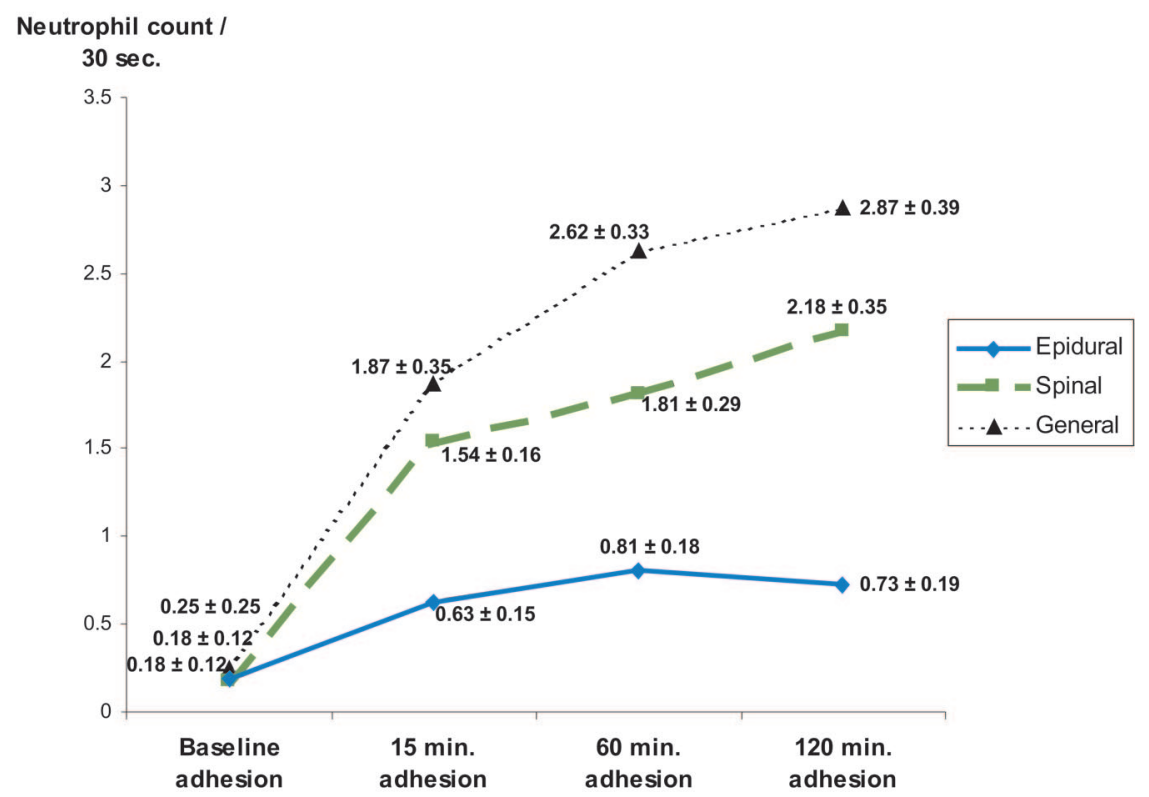

Fig. 5. Analysis of neutrophil adhesion within groups. There were no statistically significant differences in the epidural anesthesia group. Both general and spinal anesthesia groups had significant differences compared with baseline at 15, 60 and 120 minutes. Units for the numbers are number of neutrophils per 30 seconds; \pm values represent SEM ( $t$ test; ${ }^{*} p<0.05$ significant).

\section{Delta}

Adhesion

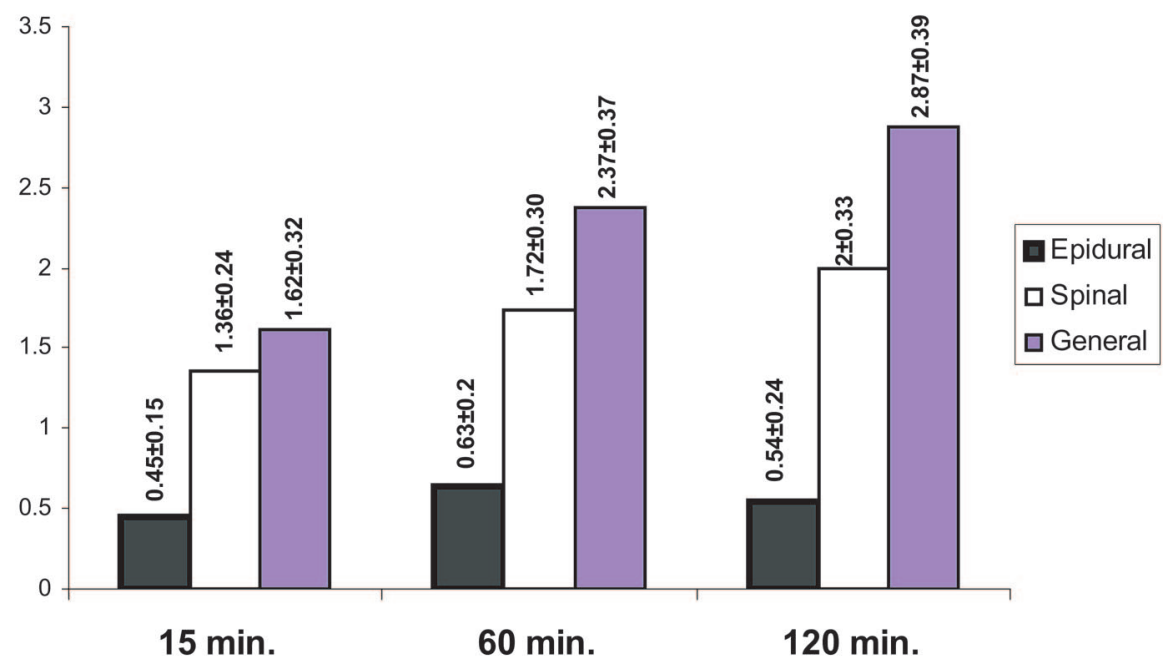

Fig. 6. Changes of adhesion of neutrophils compared with baseline ( $\Delta$-adhesion) in the three groups were analyzed. No statistically significant difference was detected between general and spinal anesthesia groups. Both of these groups had a statistically significant difference from the epidural anesthesia group at 15, 60, and 120 minutes. Units for the numbers are number of neutrophils per 30 seconds; \pm values represent SEM (analysis of variance multiple comparison test; ${ }^{*} p<0.05$ significant). 
15,60 , and 120 minutes of reperfusion are illustrated in Figure 7.

A statistically significant diameter change in the postcapillary venules compared with baseline diameter was detected at 15 minutes between the epidural and spinal anesthesia groups, and between the spinal and general anesthesia groups, but not between the epidural and general anesthesia groups.

Statistically significant change in postcapillary venules was detected when the epidural anesthesia group was compared with both general and spinal anesthesia groups at 60 minutes and at $120 \mathrm{~min}$ utes. Postcapillary venule inner diameter change was not statistically significant between the general and spinal anesthesia groups either at 60 minutes or at 120 minutes (Fig. 7).

\section{Functional Capillary Density}

In the epidural anesthesia group, statistically significant reductions in functional capillary density at 15 and 60 minutes and a more significant reduction at 120 minutes were detected (Fig. 8).

In the spinal anesthesia group, statistically significant reductions of functional capillary density with respect to the baseline value were detected at 15,60 , and 120 minutes of reperfusion. In the general anesthesia group, statistically significant reductions in functional capillary density at 15, 60, and 120 minutes were detected (Fig. 8).

The intergroup comparisons change in functional capillary density, calculated by the functional capillary counts at 15, 60, and 120 minutes of venous ischemia subtracted from baseline value for all groups are shown in Figure 9. At 15 minutes, spinal anesthesia had a statistically significant difference from the epidural and general anesthesia groups. Change in functional capillary density of the epidural anesthesia groups were statistically significant compared with other groups at 60 and 120 minutes.

\section{DISCUSSION}

Venous ischemia usually results from an error in microsurgical technique. Secondary ischemia associated with venous dysfunction appears more frequently and causes more damage than arterial or total ischemia. In one study, irreversible damage occurred very rapidly in muscle following venous ischemia, and necrosis developed in 75 per-

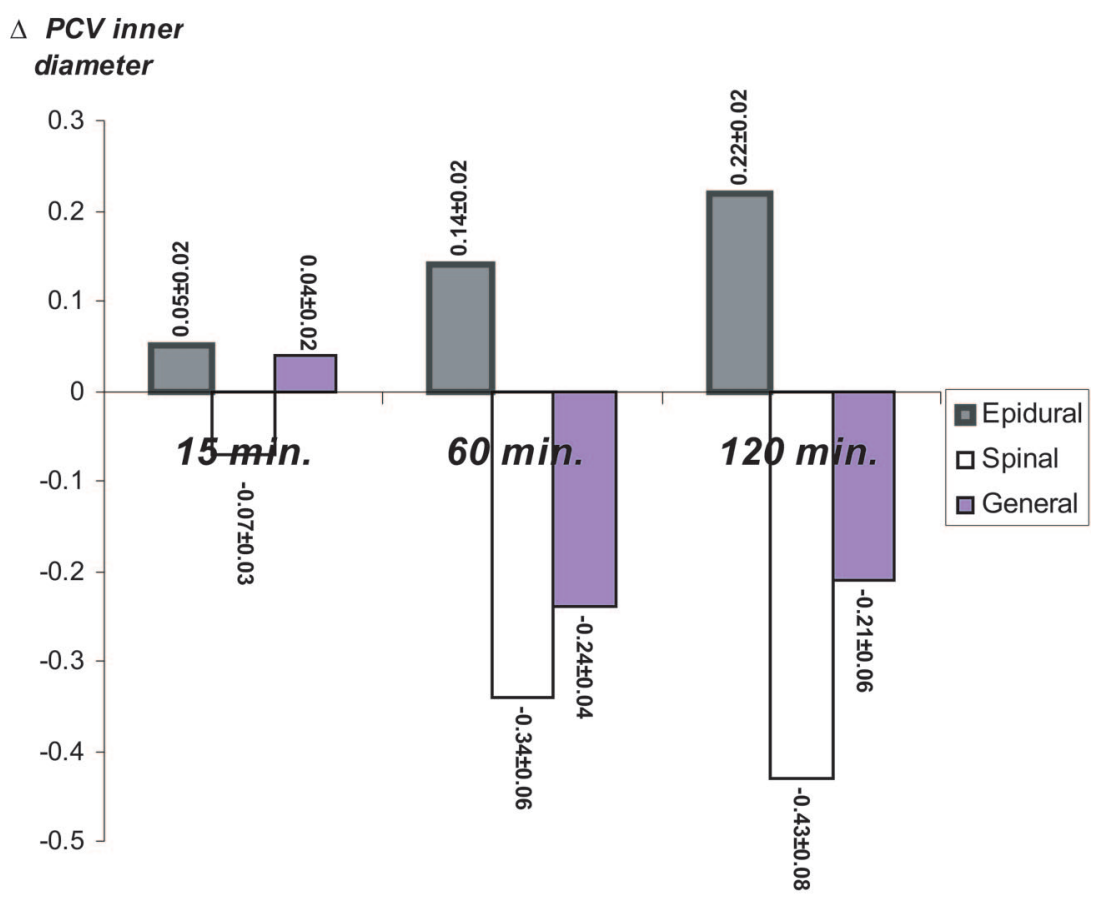

Fig. 7. The change of the postcapillary venule inner diameters compared with baseline diameters $(\triangle P C V)$ at 15,60 , and 120 minutes of reperfusion. Analysis of $\triangle P C V$ between groups revealed a statistically significant difference when epidural anesthesia was compared with general and spinal anesthesia groups at 60 and 120 minutes of reperfusion. Units for the numbers are micrometers; \pm values represent SEM (analysis of variance multiple comparison test; ${ }^{*} p<0.05$ significant). 


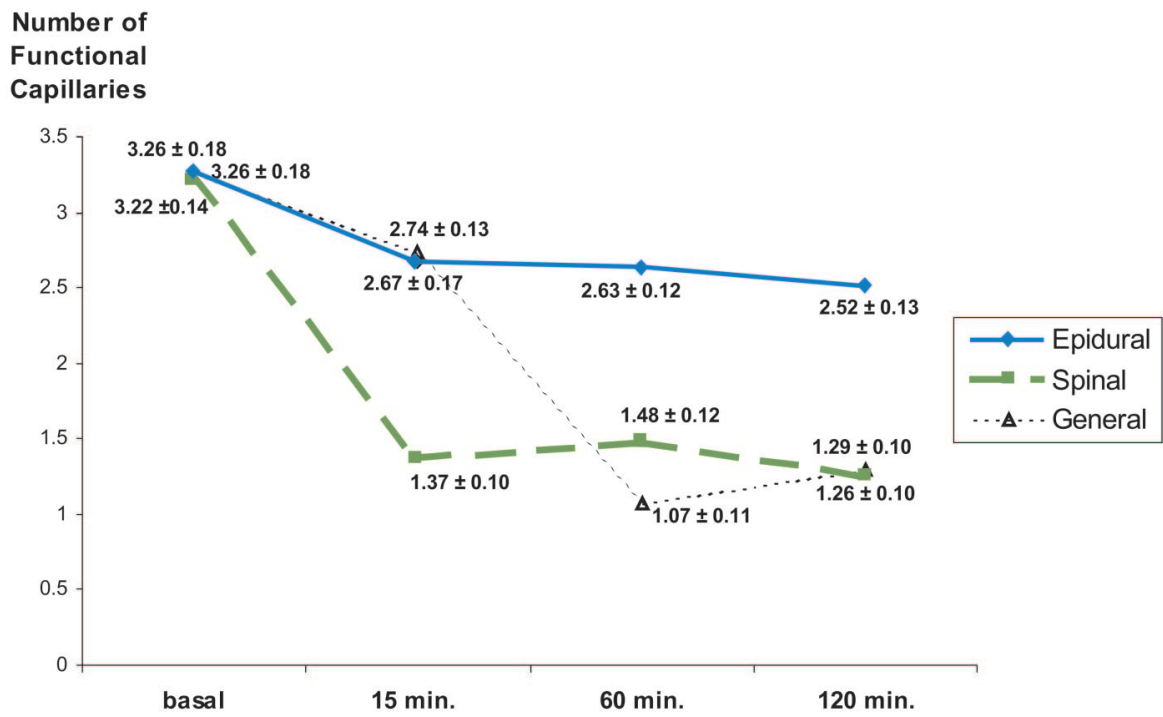

Fig. 8. Analysis of functional capillary density within groups. In all three groups a statistically significant reduction in functional capillary density was detected at 15,60, and 120 minutes compared with baseline. Units for the numbers are functional capillaries per unit area; \pm values represent SEM ( $t$ test; ${ }^{*} p<0.05$ significant).

$15 \min$.

$60 \mathrm{~min}$.

120 min.
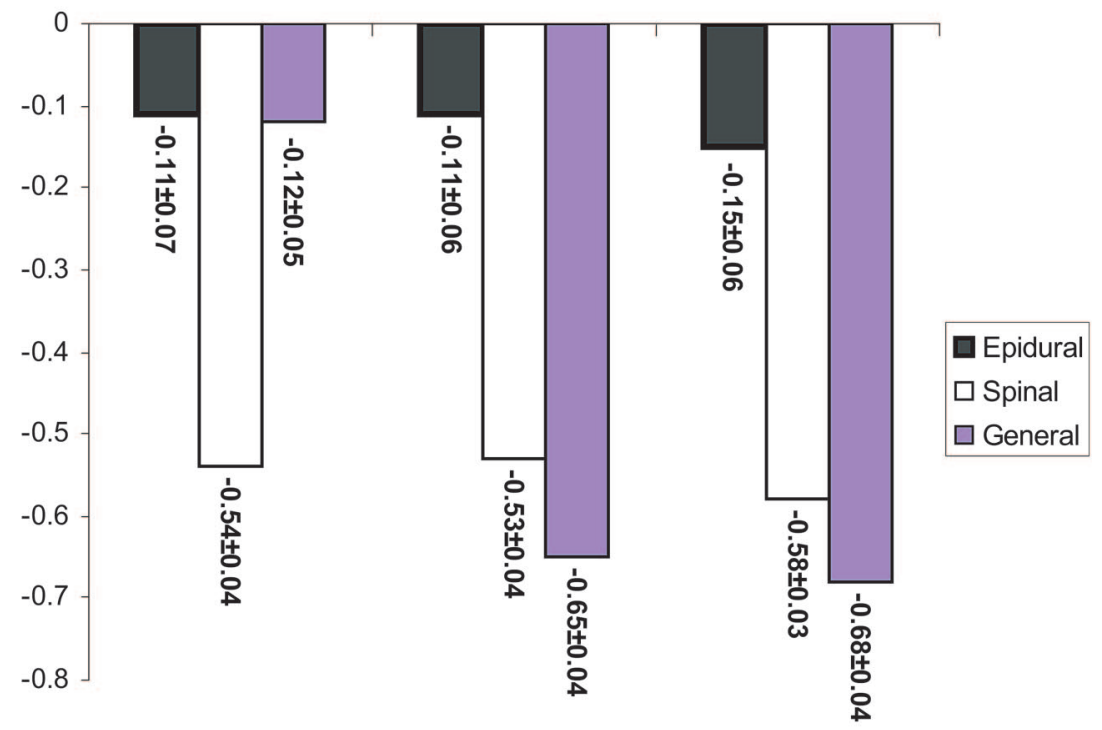

Delta

FCD

Fig. 9. The change of functional capillary density $(F C D)$ compared with baseline change in functional capillary density. Analysis of change in functional capillary density between groups revealed a statistically significant difference between the epidural anesthesia group and the spinal and general anesthesia groups at 60 and 120 minutes. Units for the numbers are functional capillaries per unit area; \pm values represent SEM (analysis of variance multiple comparison test; ${ }^{*} p<0.05$ significant). 
cent of the muscle tissue studied after 60 minutes of venous ischemia, making the early detection of venous occlusion critical to the correction of this complication..$^{22}$ The critical venous ischemia duration for muscle flaps is shorter than that for skin flaps. High metabolic activity and rigid fascial structure makes muscle tissue more vulnerable to the pressure necrosis resulting from edema and hemorrhage following venous occlusion. ${ }^{22}$ In venous occlusion, arterial blood flow continues and causes hemorrhaging from microvessels into the extravascular space. ${ }^{23,24}$ This leads to an increase in the external pressure on vessels and collapse in capillaries. The edema formed in the interstitial space after venous ischemia is not beneficial for flap survival because it prevents oxygen diffusion. ${ }^{25,26}$ This explains the transition of flaps to an anaerobic state with continued arterial blood flow following venous ischemia.

Venous ischemia almost always requires microsurgical revision of the venous anastomosis. Poor outcomes after microsurgical revision of the failed venous anastomosis attracted researchers' attention toward finding measures to decrease the progressive tissue damage following this microsurgical catastrophe. Angel et al. used deferoxamine, a free oxygen radical scavenger, in venous ischemia flaps and reported an intermediate benefit. This study reported an improvement in flap survival in the deferoxamine-treated group, and suggested free radical involvement in the mechanism of ischemia-reperfusion injury in secondary venous ischemia. ${ }^{8}$ Yucel et al. used cyclosporine A in a rat inferior epigastric artery skin flap subjected to secondary venous ischemia, aiming to reduce lipid peroxidation. This study reported decreased malondialdehyde content, lower myeloperoxidase activity and improved flap survival in the treatment group, suggesting improved flap survival after secondary venous ischemia by reducing lipid peroxidation by cyclosporine A treatment. ${ }^{27}$

We investigated the contribution of different anesthesia techniques to the microcirculation of muscle flaps subjected to venous ischemia. As freely transferred tissues are completely denervated and already sympathectomized, it has been questioned whether a sympathetic block induced by epidural anesthesia may actually decrease free flap perfusion by diverting the blood flow to the healthy vessels with lower vascular resistance. ${ }^{14}$ Other authors have suggested reduction of free flap blood flow because of a decrease in mean arterial blood pressure and cardiac output. ${ }^{12,28}$

The use of general anesthesia combined with epidural anesthesia is controversial, although there is data recommending the use of this combined anesthesia. ${ }^{1629-31}$ Scott et al. compared the efficacy of epidural and general anesthesia to general anesthesia alone in patients undergoing free tissue transfers to the lower extremity. There was a significantly lower number of major microvascular complications and a better flap survival in the combined epidural and general anesthesia group. ${ }^{16}$ Neurogenic vasoconstriction, which may result in marked reduction of blood flow through injured or revascularized tissues, is mediated through sympathetic pathways which may be blocked by long-acting local anesthetics resulting in optimal intravascular pressures and elevated flow. Phelps and colleagues showed that distal sympathetic blockade using bupivacaine protects the digital circulation against vasospasm elicited by a strong stimulus for a minimum of 7 to 8 hours. ${ }^{29}$

Because free tissue transfers are lengthy interventions, general anesthesia is preferred. ${ }^{9,10,12-16,32}$ Use of a combined epidural anesthesia is recommended in addition to this in suitable cases. ${ }^{13,14,16,33}$ Although the benefits of an epidural anesthesia are clinically known due to pain control and prevention of vasoconstriction (sympatholytic activity), there is controversy about the beneficial effect of epidural anesthesia on flap microcirculation. ${ }^{12,14,28}$ Epidural anesthesia has beneficial effects on lower extremity venous hemodynamics. ${ }^{34}$ Delis et al. quantified the venous hemodynamic changes in the lower limb during and immediately after abdominal surgery performed under epidural anesthesia and general anesthesia combined, versus under general anesthesia alone. Researchers investigated mean velocity, peak velocity, and volume flow measured at the level of the popliteal vein using duplex ultrasonography. Epidural anesthesia administered as part of general anesthesia was associated with a significant enhancement of mean volume and volume flow, improving lower extremity venous hemodynamics. ${ }^{34}$

In our study, microcirculation of the venous ischemic flaps was improved by epidural anesthesia. The beneficial effect was observed as decreased numbers of rolling and adherent leukocytes, decreased vasoconstriction in the postcapillary venules, and increased numbers of perfused capillaries in the epidural anesthesia group.

The activation of the neutrophils and eventual endothelial cell interaction consists of three steps: rolling, adhesion, and migration. ${ }^{35}$ The interaction between neutrophils and endothelial cells is mediated by a well-orchestrated sequence of interactions between adhesion molecules on both endothelium and neutrophils. The neutrophils 
are recruited to the reperfused muscle by chemotactic factors, and begin to interact with the endothelium through a process called "rolling." 36,37 This initial loose adherence is an obligatory step that is necessary for later firm adherence leading to transendothelial migration into muscle parenchyma and the physiologic sequelae, including the no-reflow phenomenon and tissue necrosis. ${ }^{38-41}$ Pronounced statistically significant differences in neutrophil functions and functional capillary density were detected, particularly at minute 120 of reperfusion, between epidural and other groups in the late reperfusion period, rendering the results more meaningful.

We found that epidural anesthesia played a protective role in the functional capillary count following venous ischemia, whereas there was a distinct reduction in the functional capillary count in the spinal and general anesthesia groups. This effect became more pronounced in the late period of reperfusion. Our study revealed decreased vasoconstriction in postcapillary venules to a statistically significant extent with epidural anesthesia following venous ischemia, compared with spinal and general anesthesia.

We have found no studies in the literature investigating the effects of spinal anesthesia on the circulation of free flaps, and we could not find any benefits of spinal anesthesia on muscle flap microcirculation. Our current experiment was designed to assess the outcomes but not the mechanisms of different anesthesia types on flap microcirculation. The reason for the detrimental effect of spinal anesthesia cannot be explained with certainty. Possible mechanisms include hemodynamic changes and the pronounced sympathectomy effect of spinal anesthesia, causing the vascular steal phenomenon which may result in a reduction of free flap blood flow. To further study these possible mechanisms, additional experiments are required.

\section{CONGLUSIONS}

In conclusion, we found that epidural anesthesia improves microcirculation and flap perfusion in the cremaster muscle island flap subjected to venous ischemia by enabling dilation of the postcapillary venules and regulating neutrophil functions. Epidural anesthesia, when administered as part of the anesthesia regimen in microsurgery, may therefore generate a marked venous flow enhancement, thus aiding in the prevention of peri-operative and postoperative venous stasis, and in cases of venous insufficiency, it may protect against venous ischemic tissue damage.

\author{
Jeffrey A. Ascherman, M.D. \\ Columbia University Medical Center \\ 161 Fort Washington Avenue, Suite 607 \\ New York, N.Y. 10032 \\ jaa7@columbia.edu
}

\section{REFERENCES}

1. Kerrigan CL, Daniel RK. Critical ischemia time and the failing skin flap. Plast Reconstr Surg. 1982;69:986-989.

2. Kerrigan CL, Zelt RG, Daniel RK. Secondary critical ischemia time of experimental skin flaps. Plast Reconstr Surg. 1984;74: 522-526.

3. Heden P, Sollevi A. Circulatory and metabolic events in pig island skin flaps after arterial or venous occlusion. Plast Reconstr Surg. 1989;84:475-481; discussion 482-483.

4. Knight KR, Angel MF, Lepore DA, et al. Secondary ischaemia in rabbit skin flaps: The roles played by thromboxane and free radicals. Clin Sci (Lond.) 1991;80:235-240.

5. May JW Jr, Chait LA, O'Brien BM, Hurley JV. The no-reflow phenomenon in experimental free flaps. Plast Reconstr Surg. 1978;61:256-267.

6. Angel MF, Narayanan K, Swartz WM, et al The etiologic role of free radicals in hematoma-induced flap necrosis. Plast Reconstr Surg. 1986;77:795-803.

7. Mellow CG, Knight KR, Angel MF, O'Brien BM. The effect of thromboxane synthetase inhibition on tolerance of skin flaps to secondary ischemia caused by venous obstruction. Plast Reconstr Surg. 1990;86:329-334.

8. Angel MF, Mellow CG, Knight KR, O’Brien BM. The effect of deferoxamine on tolerance to secondary ischaemia caused by venous obstruction. Br J Plast Surg. 1989;42:422-424.

9. Jakubowski M, Lamont A, Murray WB, de Wit SL. Anaesthesia for microsurgery. $S$ Afr Med J. 1985;67:581-584.

10. Macdonald DJ. Anaesthesia for microvascular surgery: A physiological approach. Br J Anaesth. 1985;57:904-912.

11. Faura A, Izquierdo E, Pelegri MD. Epidural vs. intradural anesthesia in ambulatory surgery (in Spanish). Rev Esp Anestesiol Reanim. 1999;46:256-263.

12. Banic A, Krejci V, Erni D, Petersen-Felix S, Sigurdsson G. Effects of extradural anesthesia on microcirculatory blood flow in free latissimus dorsi musculocutaneous flaps in pigs. Plast Reconstr Surg. 1997;100:945-955; discussion 956.

13. Berger A, Tizian C, Zenz M. Continuous plexus blockade for improved circulation in microvascular surgery. Ann Plast Surg. 1985;14:16-19.

14. Erni D, Banic A, Signer C, Sigurdsson GH. Effects of epidural anaesthesia on microcirculatory blood flow in free flaps in patients under general anaesthesia. Eur J Anaesthesiol. 1999; 16:692-698.

15. Robins DW. The anaesthetic management of patients undergoing free flap transfer. Br J Plast Surg. 1983;36:231-234.

16. Scott GR, Rothkopf DM, Walton RL. Efficacy of epidural anesthesia in free flaps to the lower extremity. Plast Reconstr Surg. 1993;91:673-677.

17. Bahar M, Rosen M, Vickers MD. Chronic cannulation of the intradural or extradural space in the rat. Br J Anaesth. 1984; 56:405-410.

18. Anderson GL, Acland RD, Siemionow M, McCabe SJ. Vascular isolation of the rat cremaster muscle. Microvasc Res. 1988;36:56-63.

19. Grant RT. The effects of denervation on skeletal muscle blood vessels (rat cremaster). J Anat. 1966;100:305-316.

20. Acland RD, Anderson G, Siemionow M, McCabe S. Direct in vivo observations of embolic events in the microcirculation 
distal to a small-vessel anastomosis. Plast Reconstr Surg. 1989; 84:280-288; discussion 289.

21. Ayhan S, Tugay C, Norton S, Araneo B, Siemionow M. Dehydroepiandrosterone protects the microcirculation of muscle flaps from ischemia-reperfusion injury by reducing the expression of adhesion molecules. Plast Reconstr Surg. 2003;111:2286-2294.

22. Gabriel A, Chaney N, Stephenson LL, Zamboni WA. Effect of total venous occlusion on capillary flow and necrosis in skeletal muscle. Plast Reconstr Surg. 2001;108:430-433.

23. Hjortdal VE, Hansen ES, Hauge E. Myocutaneous flap ischemia: Flow dynamics following venous and arterial obstruction. Plast Reconstr Surg. 1992;89:1083-1091.

24. Marzella L, Jesudass RR, Manson PN, Myers RA, Bulkley GB. Functional and structural evaluation of the vasculature of skin flaps after ischemia and reperfusion. Plast Reconstr Surg. 1988;81:742-750.

25. Angel MF, Mellow CG, Knight KR, O’Brien BM. Secondary ischemia time in rodents: Contrasting complete pedicle interruption with venous obstruction. Plast Reconstr Surg. 1990; 85:789-793; discussion 794-795.

26. Vollmar B, Westermann S, Menger MD. Microvascular response to compartment syndrome-like external pressure elevation: An in vivo fluorescence microscopic study in the hamster striated muscle. J Trauma 1999;46:91-96.

27. Yucel A, Senyuva C, Andican G, et al. Secondary venous ischemic injury associated with neutrophil infiltration and lipid peroxidation: Amelioration of injury by cyclosporin A in a rat inguinal island flap. Ann Plast Surg. 2000;45:54-60.

28. Van Twisk R, Gielen MJ, Pavlov PW, Robinson PH. Is additional epidural sympathetic block in microvascular surgery contraindicated? A preliminary report. Br J Plast Surg. 1988;41:37-40.

29. Phelps DB, Rutherford RB, Boswick JA Jr. Control of vasospasm following trauma and microvascular surgery. J Hand Surg (Am.) 1979;4:109-117.

30. Sigurdsson GH, Thomson D. Anaesthesia and microvascular surgery: Clinical practice and research. Eur J Anaesthesiol. 1995;12:101-122.

31. Taras JS, Behrman MJ. Continuous peripheral nerve block in replantation and revascularization. JReconstr Microsurg. 1998; $14: 17-21$.
32. Sigurdsson GH, Banic A, Wheatley AM, Mettler D. Effects of halothane and isoflurane anaesthesia on microcirculatory blood flow in musculocutaneous flaps. Br J Anaesth. 1994;73: 826-832.

33. Inberg P, Tarkkila PJ, Neuvonen PJ, Vilkki S. Regional anesthesia for microvascular surgery: A combination of brachial plexus, spinal, and epidural blocks. Reg Anesth. 1993;18:98102.

34. Delis KT, Knaggs AL, Mason P, Macleod KG. Effects of epidural-and-general anesthesia combined versus general anesthesia alone on the venous hemodynamics of the lower limb: A randomized study. Thromb Haemost. 2004; 92:1003-1011.

35. Angel MF, Ramasastry SS, Swartz WM, Basford RE, Futrell JW. Free radicals: Basic concepts concerning their chemistry, pathophysiology, and relevance to plastic surgery. Plast Reconstr Surg. 1987;79:990-997.

36. Elgebaly SA, Hashmi FH, Houser SL, Allam ME, Doyle K. Cardiac-derived neutrophil chemotactic factors: Detection in coronary sinus effluents of patients undergoing myocardial revascularization. JThorac Cardiovasc Surg. 1992;103:952959.

37. Dreyer WJ, Smith CW, Michael LH. Canine neutrophil activation by cardiac lymph obtained during reperfusion of ischemic myocardium. Circ Res. 1989;65:1751-1762.

38. Kubes P, Jutila M, Payne D. Therapeutic potential of inhibiting leukocyte rolling in ischemia/reperfusion. J Clin Invest. 1995;95:2510-2519.

39. Davenpeck KL, Gauthier TW, Albertine KH, Lefer AM. Role of P-selectin in microvascular leukocyte-endothelial interaction in splanchnic ischemia-reperfusion. Am J Physiol. 1994; 267:H622-H630.

40. Geng JG, Bevilacqua MP, Moore KL, et al. Rapid neutrophil adhesion to activated endothelium mediated by GMP-140. Nature 1990;343:757-760.

41. Jerome SN, Dore M, Paulson JC, Smith CW, Korthuis RJ. P-selectin and ICAM-1-dependent adherence reactions: Role in the genesis of postischemic no-reflow. Am J Physiol. 1994; 266:H1316-H1321. 